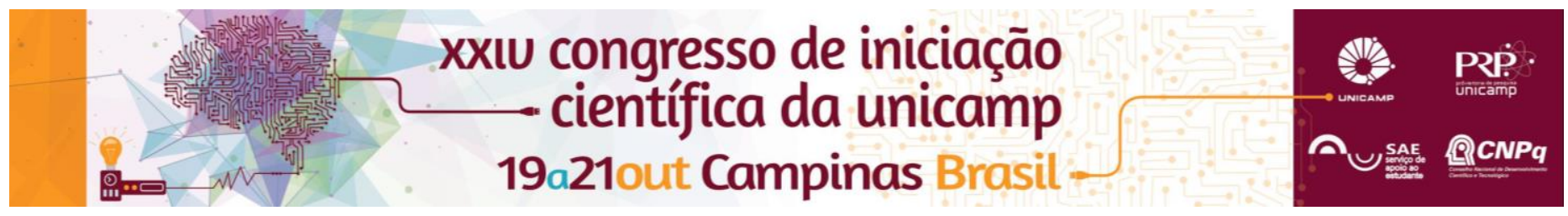

\title{
Prosa de ficção em catálogos de B. L. Garnier no Rio de Janeiro (1863-1880)
}

\author{
Fernanda G. Gaspar*, Rayssa M. Sousa, Sabrina de S. Teco (PIBIC-EM).
}

\section{Resumo}

Este trabalho resulta de estágio do Programa Institucional de Bolsa de Iniciação Científica para o Ensino Médio (PIBICEM-CNPq), realizado junto ao projeto temático "A Circulação Transatlântica dos Impressos: a globalização da cultura no século XIX (1789-1914)", financiado pela FAPESP. Nossa atividade consiste na transcrição e pesquisa de dados de catálogos de livreiro do século XIX e na sua inserção no banco de dados CiTrlm (Circulação Transatlântica dos Impressos). A partir dos recursos desse banco, para o qual contribuímos ao longo de nosso estágio, apresentaremos informações a respeito da circulação de obras de prosa ficcional a partir de catálogos do livreiro-editor Baptiste Louis Garnier entre 1863 e 1880, tais como a procedência dos títulos e a presença de traduções.

Palavras-chave: Prosa Ficcional, Catálogos de Livreiro, Circulação.

\section{Introdução}

Durante o estágio PIBIC-EM, realizamos pesquisas que contribuíram para a alimentação do Banco de dados CiTrlm por meio da identificação de informações concernentes aos títulos anunciados em catálogos de livreiros do século XIX. A partir desses títulos, buscávamos identificar dados que complementassem informações a seu respeito, como: autoria, quando ausente; título da obra original, quando se tratava de tradução, e gênero. De posse dessas informações, passávamos à sua inserção no banco de dados, que se constitui como fonte de consulta e análise para os pesquisadores do grupo "A Circulação Transatlântica dos Impressos...". Neste trabalho, o corpus selecionado é de 48 catálogos de Baptiste Louis Garnier, o maior livreiro-editor do Rio de Janeiro no período. Para a nossa análise, utilizamos a ferramenta de busca avançada do banco de dados CiTrlm, que nos forneceu tabelas com dados a respeito dos títulos anunciados, a fim de conhecermos a constituição do repertório oferecido ao público leitor e as suas implicações no comércio de livros ficcionais.

\section{Resultados e Discussão}

De acordo com nossos propósitos, foram geradas tabelas contendo os seguintes dados: título da publicação, língua original, língua de publicação e ocorrências (número de aparições das obras). Com isso, foi possível construir gráficos que ilustram a presença de traduções que circulavam no período.

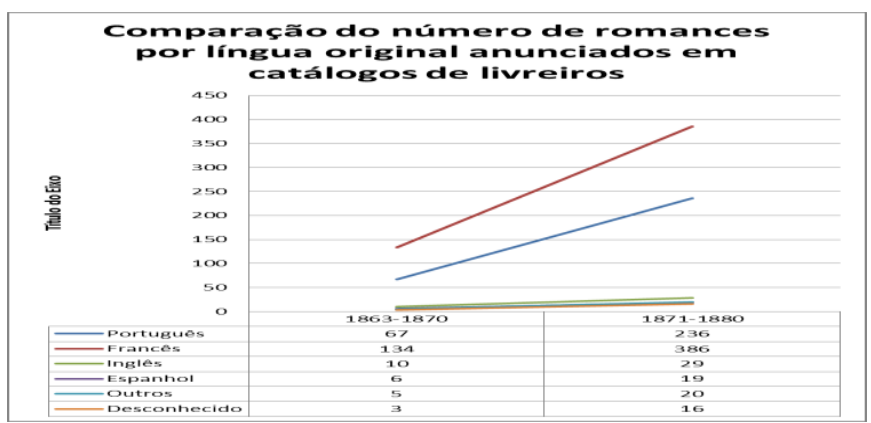

Este gráfico aponta que, de uma década para outra, aumentou o número de romances em circulação em todas as línguas encontradas. Os títulos em francês foram os que apresentaram maior crescimento em relação aos demais idiomas.

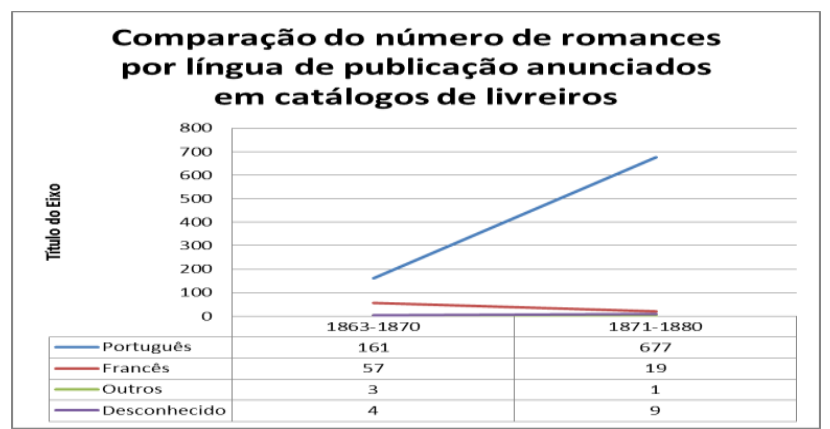

Este gráfico demonstra que o número de títulos publicados em português, que já era maioria nos anos 1860, aumentou exponencialmente na década seguinte. Ou seja, apesar de os romances serem, em sua maioria, originalmente estrangeiros (57\% para todo o período entre 1863 e 1880), a língua de circulação passava a ser principalmente o português.

\section{Conclusões}

Percebemos, por meio desses dados, que havia uma intensa circulação de romances estrangeiros nas prateleiras de Garnier. O público leitor carioca tinha à disposição textos de diversas partes do mundo, além da literatura original de língua portuguesa, o que demonstra uma variedade cultural de expressão literária. Além disso, a alta presença de títulos de origem francesa comprova a importância da França como polo irradiador de literatura no século XIX, e a predominância da língua portuguesa representa o fortalecimento do mercado de tradução nesse idioma. Por fim, com esta pesquisa, pudemos experimentar da vivência acadêmica e compreender o desenvolvimento de trabalhos de caráter científico através de fontes primárias, metodologias de análises e interpretação de dados, com uso de recursos tecnológicos, além de contribuir com o desenvolvimento das atividades dos pesquisadores do laboratório e do projeto temático no qual atuamos.

\section{Agradecimentos}

Agradecemos à orientadora Márcia Abreu, aos monitores Julio César Modenez, Valéria Cristina Bezerra e Moizeis Sobreira. Agradecemos ainda ao Conselho Nacional de Desenvolvimento Científico e Tecnológico (CNPq) pelo financiamento e à Universidade Estadual de Campinas (UNICAMP) pela oportunidade. 